\title{
O Ensino da dança e as relações de gênero e sexualidade
}

\author{
La enseñanza de la danza y las relaciones de género y sexualidad \\ The dance teaching and the relations of gender and sexuality
}

Giuliano Souza Andreoli ${ }^{1}$

\begin{abstract}
Resumo
O objetivo deste artigo é discutir a temática da diversidade sexual e de gênero no âmbito do ensino da Dança, na interface entre a dança e a educação. Para tanto, utiliza como referencial o campo dos Estudos de Gênero, a partir da teorização pós-estruturalista (SCOTT, 1995; MEYER, 2003; LOURO, 2007, 2013a, 2013b, BUTLER, 2017). Apresentarei uma síntese de algumas discussões internacionais e nacionais que tem sido feitas, há décadas, por teóricos das áreas da Dança, Educação e Educação Física. Problematizarei como a dança e a aula de dança pode se configurar em espaço de experiências generificadas. Por fim, procurarei apontar quais alternativas os estudos sobre esse tema têm apontado para os modos como ensinamos e fazemos dança.
\end{abstract}

Palavras-Chave: dança; gênero; sexualidade; educação.

\section{Resumen}

El objetivo de este artículo es discutir la temática de la diversidad sexual y de género en el ámbito de la enseñanza de la Danza, en la interfaz entre la danza y la educación. Para ello, utiliza como referencial el campo de los Estudios de Género, a partir de la teorización postestructuralista (SCOTT, 1995; MEYER, 2003; LOURO, 2007, 2013a, 2013b, BUTLER, 2017). Presentaré una síntesis de algunas discusiones internacionales y nacionales que han sido hechas hace décadas por teóricos de las áreas de la Danza, Educación y Educación Física. Problematizé cómo la danza y la clase de danza pueden configurarse en espacio de experiencias generificadas. Por último, procuraré señalar qué alternativas los estudios sobre este tema han apuntado a los modos como enseñamos y hacemos danza.

Palabras claves: danza; género; sexualidad; educación.

\begin{abstract}
In this article, my goal is to discuss sex and gender diversity in dance teaching, as an interface between dance and education. To do so, I use Gender Studies as main reference point, from poststructuralist theories (Scott 1995; Meyer 2003; Louro 2007, 2013a, 2013b; Butler 2017). I present an outline of some discussions, both domestic and international, that have been carried out for decades by theorists on Dance, Education and Physical Education. I argue how dance and dance classes can be configured as spaces of gender experiences. Lastly, I point out some alternatives pointed out by studies on the theme, on how we teach and create dance.
\end{abstract}

Keywords: dance; gender; sexuality; education.

\footnotetext{
${ }^{1}$ Universidade Estadual do Rio Grande do Sul (UERGS). Atua na área de Teoria da Dança, com ênfase na relação entre Dança e Educação, Dança e Ciências Humanas (Antropologia, Sociologia, História, Estudos Culturais, Estudos de Gênero). E-mail: giulianosouzandreoli@yahoo.com.br.
} 


\section{Introdução}

O objetivo deste artigo é discutir o tema da diversidade sexual e de gênero no âmbito do ensino da Dança, na interface entre a dança e a educação. Para tanto, utiliza como referencial a abordagem do campo dos Estudos de Gênero, a partir de uma teorização pósestruturalista (SCOTT, 1995; MEYER, 2003; LOURO, 2007, 2013a). A partir disso, apresentarei uma revisão bibliográfica das discussões internacionais e nacionais que tem sido feitas, há décadas, por teóricos das áreas da Dança, da Educação e da Educação Física.

Inicialmente, conceituarei a categoria gênero. Depois, discutirei os aspectos culturais e históricos envolvidos na relação entre dança e gênero, tais como analisados pela literatura referenciada. Em seguida, descreverei ações pedagógicas que têm sido apontadas como reprodutoras de relações sociais e de símbolos relacionados a lógicas culturais sexistas, heteronormativas ou cisnormativas, bem como ações pedagógicas voltadas para a transformação desses significados e das relações sociais.

Tendo como preocupação a permanente reflexão crítica para pensarmos os modos como se ensina dança, fundamentarei, assim, a problemática de como a dança e as aulas de dança podem se configurar em espaços de experiências generificadas e generificantes. Procurarei, com isso, contribuir para a reflexão pedagógica acerca das condições a partir das quais os processos de ensino da dança são constituídos, entendendo o papel que podem ter na reprodução, desconstrução ou transgressão de normas culturais de gênero e de sexualidade.

\section{O Conceito de Gênero}

Gênero é uma categoria de percepção do mundo baseada na distinção binária entre “masculino" e "feminino" (NICHOLSON, 2000; BUTLER, 2017). Historicamente, em nossa civilização, essa percepção por muito tempo concebeu as desigualdades sociais sofridas pelas mulheres como determinadas pela sua suposta natureza inferior (LAQUEUR, 2001). Ao longo do século XX, as ciências humanas demonstraram, através de estudos comparativos entres diferentes sociedades, que os papéis sexuais não eram determinados pela diferença biológica, mas sim produto da educação, variando social e historicamente (MEAD, 1988).

Para desconstruir os discursos que justificavam diferenças sociais entre homens e mulheres a partir da natureza, as lutas feministas influenciaram, a partir dos anos de 1960, as ciências humanas, constituindo o campo dos Estudos das Mulheres. Posteriormente, as 
feministas americanas utilizam o termo "gender" para demarcar a "rejeição do determinismo biológico implícito nos termos 'sexo' e 'diferença sexual'." (SCOTT, 1995, p. 72).

Da forma como foi concebido a partir de Scott (1995), o conceito de gênero trouxe um novo olhar: estudar a constituição das identidades subjetivas tanto de homens quanto de mulheres, de uma forma relacional (LOURO, 2001). Pois a perspectiva que se instaurou a partir da perspectiva pós-estruturalista concebeu o gênero como indo para além do mero desempenho de "papéis" (LOURO, 2007), estando relacionado aos símbolos culturalmente disponíveis e aos conceitos normativos sobre o masculino e o feminino, cujos valores e significados são reproduzidos por diferentes práticas sociais, instâncias, espaços ou campos de saber que os colocam em operação, incluindo a economia, o Estado e instituições sociais: a educação, a igreja, etc. (CONNEL, 1995; SCOTT 1995, MEYER, 2004).

Gênero é confundido, no senso comum, com sexualidade ou orientação sexual. A orientação sexual é como cada indivíduo exerce uma configuração psíquica do desejo e da atração que sente por outros indivíduos. Alguns termos nomeiam as configurações possíveis: homossexualidade, bissexualidade, heterossexualidade, assexualidade ou pansexualidade (NASCIMENTO, 2013). Já sexualidade é mais ampla, pois inclui os dispositivos históricos que reúnem práticas sociais em torno do corpo. A sexualidade inclui uma rede de significados onde a estimulação dos corpos, a intensificação dos prazeres, a incitação ao discurso, o reforço do controle e das resistências, encadeiam-se uns aos outros (FOUCAULT, 2003).

Na perspectiva aqui adotada, gênero e orientação sexual se referem à construção de identidades culturais, assim como a raça, a etnia ou a classe. Portanto, resultam dos sistemas simbólicos e de classificação, criados por meio da linguagem, a partir dos quais os indivíduos se posicionam como sujeitos de uma cultura (WOODWARD, 2005). E como a cultura é um campo político, repleto de lutas por imposição de sentidos (HALL, 1997; CANCLINI, 2005), gênero e sexualidade incluem a formação de regimes de representações hegemônicas, que são "sistemas de significação cuja pretensão consiste em expressar o humano em sua totalidade" (SILVA, 1999), que podem estar relacionados à formação do senso comum, à cristalização de conceitos e de preconceitos.

Conforme Scott (1995), gênero é uma forma primária de significar relações de poder. Para Butler (2017), o poder opera na própria produção do "falocentrismo": a lógica que constrói uma oposição binária entre "masculinidade" e "feminilidade", sendo o masculino o polo mais valorizado. E também da "heteronormatividade": a "obsessão com a sexualidade normalizante, através de discursos que descrevem a situação homossexual como desviante" (BRITZMAN, 1996, p. 79). Além desses mecanismos de regulação dos gêneros e das 
sexualidades, existe ainda um terceiro que é a "cisnormatividade": uma vez que a cultura converte determinadas partes dos corpos em definidores de gênero, cria-se uma relação determinista entre sexo biológico e gênero que privilegia as pessoas 'cisgênero' em detrimento das pessoas 'transgênero', por serem socialmente vistas como "alinhadas" dentro de seu corpo e de seu gênero (BUTLER, 2000; LOURO, 2013b; PRECIADO, 2014).

\section{Gênero e Dança na História e na Cultura}

Uma produção internacional consistente de estudos sobre o tema do ensino da dança e as relações de gênero (STINSON, 1998, 2005; SANDERSON, 2001; GARD, 2001; RISNER, 2007, 2009, 2014; MIGDALEK, 2015; ALLEN-COLLINSON, CLEGG e OWTON, 2016) têm apontado, há décadas, para a importância do gênero na organização de todas as práticas sociais relacionadas à dança, desde a participação ou não de estudantes em aulas até as formas de produzir dança e as atitudes pedagógicas dos professores e professoras de dança.

Tais estudos indicam que a grande maioria da população de alunas de dança nos espaços não-formais são mulheres (VAN DYKE, 1996; SANDERSON, 2001) e que as professoras de dança são quatro vezes mais propensas a serem do sexo feminino do que masculino (RISNER, 2014). Enquanto o esporte é frequentemente significado como uma experiência masculina, relacionado com características supostamente viris, como "tenacidade mental" (COOK et al., 2014), a dança é vista como uma "atividade efeminada e suspeita para um corpo masculino" (MIGDALEK, 2015, p.76). No Brasil, alguns estudos (SOUZA, 2007; SANTOS, 2009a; SANTOS 2009b), têm apontado para a mesma conjuntura cultural.

Enquanto a dança, em muitas culturas, tem sido vista como uma atividade apropriada ao masculino, o paradigma cultural ocidental situa a dança como uma forma de arte feminina, desde o século XVIII (HASBROOK, 1993, HANNA, 1999). Para muitos, o elemento chave é entender a "feminização da dança teatral no Ocidente" (RISNER, 2007, p.967), relacionada à história do balé e à sua hegemonia simbólica dentro do campo da dança (SOUZA, 2007).

Até o século XVIII, as danças de corte faziam parte da formação da classe nobre, tanto do gênero masculino como do feminino, funcionando como forma de generificar os corpos de homens e também de mulheres. Na medida em que o balé foi se configurando como uma modalidade mais complexa e espetacular, a moral vigente passou a excluir as mulheres. E a figura masculina foi adquirindo uma presença central nos palcos: "mulheres bem educadas não apareciam em palcos públicos" (HANNA, 1999, p. 184). Os homens, entre eles os reis Luís XIII e Luís XIV, muitas vezes, dançaram papéis cênicos femininos. 
A partir da Revolução Industrial, as representações hegemônicas de masculinidade e de feminilidade se modificaram. Com a clivagem entre a economia doméstica e a economia pública, que transferiu a produção manufatureira da casa para a fábrica, começou a ser forjada a esposa e a mãe como modelos ideais. Assim, a exaltação da maternidade, com vistas a limitar a mulher à esfera do lar e à função de procriação, instituiu a inferioridade das mulheres com mais forçado que nunca (DAVIS, 2016). No que diz respeito aos homens, o que passou a ser, então, cobrado como o comportamento ideal para os "verdadeiros" homens "viris" foi a eficiência, a racionalidade e a produtividade (KIMMEL, 1998; HANNA, 1999).

Sendo assim, até o século XVIII, a dança masculina, era:

[...] um meio eficaz para "formar" homens - isto é, para generificar corpos masculinos. Estaca associado a um modelo de masculinidade hegemônico, denominado por Kimmel (1998) de o "patriarca gentil": o aristocrata nobre europeu, que "provava" a sua masculinidade através da exibição de gestos corporais suaves e delicados e de uma certa sensualidade (ANDREOLI, 2011, p.161).

Mas, a partir da nova etapa do capitalismo industrial, a dança perdeu o prestígio e foi desvalorizada enquanto profissão. E a dança masculina passou a ser associada à "frouxidão moral" e os embaraços à produtividade econômica. (HANNA, 1999, p.184).

Somente quando a dança cênica ocidental recebeu baixa remuneração e pouco interesse pela carreira por parte dos homens, começou a apresentar abertura à participação de mulheres. As primeiras bailarinas eram todas mulheres de baixa renda, que começaram a ver na dança uma alternativa às fábricas, à agricultura ou ao emprego doméstico, sendo “marcadas a fogo pelos estigmas da classe trabalhadora" (HANNA, 1999, p.187).

A partir do século XIX, o balé deixa de ser uma dança associada à figura dos homens para se tornar predominantemente uma dança de mulheres, pois associa-se às representações hegemônicas de feminilidade do romantismo. O marco principal do romantismo no balé foi com a obra 'La Sylphide', de 1830. Como afirma Hanna (1999, p.188), a bailarina Marie Taglioni "sintetizou a fantasiosa e etérea peça central da era romântica, em La Sylphide". Tal símbolo se liga à representação de uma mulher pura, casta, virgem, espiritual, quase etérea e ligada à graça, à leveza e à delicadeza de movimentos.

Até hoje, para muitas meninas, aulas de dança são relacionadas a representações simbólicas próximas a este ideal de feminilidade do romantismo (STINSON, 1998, SANTOS 2009a). Começando cedo, por volta dos três anos, muitas meninas de classe média e alta geralmente crescem na prática do balé, colocadas por suas mães. As lições sobre feminilidade 
aprendidas nessa dança são as mesmas que as meninas aprendem em outros lugares: ser silenciosa, obediente, graciosa e bonita. Sendo assim, um treinamento como esse reforça expectativas da sociedade em relação às mulheres (STINSON, 1988).

O estudo de Santos (2009a), realizado no Brasil, também observou forte associação entre os movimentos e gestos corporais treinados no balé, bem como os figurinos e todo um estilo de vida, com um modelo hegemônico de feminilidade. A pesquisadora constatou que, para as meninas, o treinamento no balé significa um processo de aprendizado de uma maneira de serem femininas. E estava relacionado com um determinado modelo específico de feminino: bela, educada, civilizada, elegante, graciosa, etc. O que demonstra que o balé ainda opera como uma eficiente pedagogia da feminilidade, ligado a um ideal romântico de feminino, sendo uma forma eficiente para "formar" mulheres de um determinado tipo.

Essa "feminização" histórica do simbolismo de gênero que permeia o corpo no universo da dança cênica persiste, mesmo depois da vertente russa do balé ter valorizado a figura de muitos bailarinos homens na cena. E ela permanece relacionada não apenas ao balé, mas a todas as danças com proximidade estética. Assim, a participação masculina na dança europeia ocidental permanece uma atitude culturalmente suspeita para muitos meninos, adolescentes e jovens (SANDERSON, 2001) e leva, muitas vezes, à estigmatização e ao bullying daqueles homens que dançam (POLASEK; ROPER, 2011; RISNER, 2014).

Esta estigmatização está ligada ao processo que Butler (2017) refere como o mecanismo da regulação da sexualidade por meio da desqualificação do gênero. Esse mecanismo, que afirma que o oposto da masculinidade é a falta de masculinidade, regula a construção do gênero masculino em nossa cultura, a partir da lógica heteronormativa. Dentro dessa lógica cultural, o homem que dança é visto como "afeminado", termo pejorativo que reforça uma oposição hierárquica entre masculino e feminino e entre o homem supostamente menos viril e os modelos hegemônicos de masculinidade heterossexual.

Entretanto, embora fora do universo da dança, todos os homens que dançam (de qualquer orientação sexual) estão sempre em perigo de não serem considerados homens "reais", uma vez situado dentro dele, os homens, muitas vezes, experimentam posições privilegiadas (MEGLIN; BROOKS, 2012; WRIGHT, 2013; RISNER, 2014; CLEGG; OWTON; ALLEN-COLLINSON, 2016). Tais privilégios incluem, por exemplo, ocupar posições mais altas em companhias, tais como cargos de coreógrafos ou diretores artísticos. Ou mesmo quando ocupam a posição de bailarino, em muitos contextos, os homens tendem a serem mais valorizados, em termos de oportunidades, no mercado de trabalho da dança. 
Além disso, enquanto a generificação de certas danças, como o balé, emerge de uma compreensão restrita do que é ser masculino e gera a relutância na participação de homens, outras danças já são vistas como masculinas e muitas vezes atraem mais homens (HOLDSWORTH, 2013). As danças urbanas, por exemplo, podem aumentar a popularidade e atratividade para os meninos, dada a significação que se faz dessas danças como um símbolo de masculinidade (PASCOE, 2005).

Em um estudo na Alemanha, Weller (2005) analisou essa representação hegemônica de masculinidade que permeia as danças urbanas. A autora estudou um grupo de meninas buscando conquistar espaço em um grupo de dança, na cidade de Berlim. E relatou que, inicialmente, as jovens tiveram que treinar sem o conhecimento dos rapazes para não serem impedidas por eles. E conclui que, mesmo depois de aceitas por causa do resultado do seu esforço e da qualidade da sua dança, o interesse pela sua participação no grupo se restringiu a um papel secundário (WELLER, 2005).

No Brasil, Santos (2009b) observa que, embora seja aceito nas danças urbanas, a tendência é ele ter que dançar reafirmando atributos culturalmente considerados próprios do "verdadeiro" masculino: força, destreza, coragem. O homem que pratica danças urbanas é subjetivado por discursos masculinizantes que, através de jogos de verdade, exercem controle, manutenção e produção da masculinidade 'verdadeiramente hegemônica'. Sendo assim, as danças urbanas são simbolizadas como um terreno masculino dentro do universo geral da dança: músicas, roupas, acessórios, movimentos coreográficos e acrobáticos devem sempre reafirmar uma suposta "virilidade". Na Inglaterra, Clegg, Owton, Allen-Collinson (2016, p.10-11) chegaram à mesma conclusão, constatando que essas danças eram consideradas pelos meninos como uma "coisa legal, devido a esta incorporação de características associadas à masculinidade hegemônica (altos níveis de energia, força e competitividade)."

Algumas danças, por outro lado, seguem se configurando como espaços bastante femininos. Como observam Saraiva e Camargo (2008), é significativo, no exemplo da dança do ventre, a noção de ligação da mulher à natureza e ao corpo, aos ciclos naturais, à menstruação, à gravidez, à menopausa e aos ciclos de fertilidade. A Dança do Ventre é, por isso, considerada uma "dança de mulher" e seus movimentos são muitas vezes tidos como não adequados para o corpo masculino. Outros elementos caracterizam-na, também, como dança de sedução e erótica, articulados à educação para as mulheres e reforço de normas de gênero.

No estudo etnográfico de Menezes Neto (2008), observa-se que no caso das danças populares brasileiras, onde tanto homens quanto mulheres são bem aceitos, há uma delimitação muito nítida de espaços específicos para o homem e para a mulher, de modo a 
reafirmar uma participação binária e desigual. Essa generificação das ações corporais presente nas danças a dois, é também característica das danças de salão, onde a ação de condução do movimento do par é associada à masculinidade, na figura do "cavalheiro" e a ação de ser conduzida, uma ação que é significada como mais passiva, é associada à mulher, a "dama". Assim, o ensino tradicional da dança de salão age como um mecanismo de identificação entre sexo, gênero e orientação sexual, sendo uma técnica de regulamentação e programação dos corpos e dos sujeitos. Ela não é baseada em diferenças prévias entre homens e mulheres, ela constrói essas diferenças: constrói a mulher como dama - frágil, delicada, submissa, graciosa, sensual, atenta e obediente aos comandos dos homens - e constrói o homem como cavalheiro - forte, soberano, dominador, viril, responsável por cuidar da mulher e determinar seus movimentos, seus rumos (PAZZETO e SAMWAYS, 2018).

Em outros contextos, o reforço de concepções hegemônicas de gênero pode revelar-se não somente na significação que se dá para a performatividade dos gestos, das ações motoras ou dos movimentos das coreografias relacionados a ideais de masculinidade ou feminilidade, mas em outras dimensões da vida social do indivíduo. Isso é demonstrado nos estudos de Souza (2007) e Andreoli (2011) no contexto das companhias profissionais de dança no Brasil, onde a trajetória pessoal dos sujeitos é analisada a partir do enfoque do gênero. Por exemplo, embora os homens tenham um início quase sempre mais tardio do que as mulheres e precisam superar inúmeras "barreiras culturais" para dançar (SOUZA, 2007), quando exibem traços característicos da masculinidade hegemônica do tipo "self-made-man" (sucesso, eficiência, independência econômica, espírito empreendedor), tais atributos costumam agregar valores positivos para a sociedade, atenuando tais barreiras (ANDREOLI, 2011).

Em geral, o que esses estudos têm observado é que ao serem socializados dentro de uma cultura com forte binarismo de gênero, os homens e as mulheres na dança sempre tenderão a perpetuar a dicotomia dos gêneros na perspectiva de significar certas danças como "femininas" e outras como "masculinas". Pois, como qualquer outra construção identitária, a construção do gênero depende de um conjunto de símbolos culturalmente disponíveis (SCOTT, 1995). E as representações culturais hegemônicas e binárias de gênero sempre tenderão a generificar as danças, os movimentos e gestos corporais utilizados na dança, as roupas etc. E mesmo quando os indivíduos rompem com um algum nível das normas culturais dominantes, eles também podem fazer isto dependendo da afirmação de tipos específicos de políticas de gênero, estando em alguma medida, portanto, atuando dentro das mesmas normas hegemônicas. 
No entanto, também é importante ressaltar a existência de resistências a essas normas e rupturas com as representações hegemônicas de gênero. Se as mulheres, por um lado, permaneceram ao longo da história do Ocidente dentro de um processo de luta por sua legitimação e valorização enquanto artistas que ainda está longe de ter se acabado, houve importantes conquistas. Um exemplo histórico é como a Dança Moderna, nos Estados Unidos do início do século XX, foi marcada pela emergência de importantes mulheres coreógrafas, tais como Isadora Duncan, Ruth Dennis ou Martha Graham. Tal acontecimento esteve vinculado ao descontentamento com os papéis sociais atribuídos à mulher naquela época (HANNA 1999).

\section{Gênero, Dança e Educação}

Como observa Connel (1995), o gênero se dirige fundamentalmente aos corpos. Existe todo um senso de vida estabelecido em torno de distinções corporais, relacionadas a gênero. Há um jeito corporal de ser masculino e um jeito corporal de ser feminino, com atitudes e movimentos socialmente entendidos como naturais para cada sexo, que nós vivenciamos "como certas tensões musculares, posturas, habilidades físicas, formas de nos movimentar, e assim por diante" (CONNEL, 1995, p.189).

Louro (2013b) também afirma que definir alguém como homem ou mulher significa nomear, classificar ou "marcar" o seu corpo no interior da cultura. O processo de educação de homens e mulheres em sociedade implica no processo ensino/aprendizagem de valores, posturas e movimentos corporais considerados masculinos ou femininos. Para que isso ocorra, é necessário que normas regulatórias de gênero e sexualidade sejam continuamente reiteradas e refeitas. A partir delas, os corpos são "datados", fazendo-se históricos e situados, e recebem um valor social que lhes dá uma legitimidade como sujeitos. (LOURO, 2013b, p.89).

Assim, além de ser um campo interessante para a análise dos valores da cultura e da sociedade, a articulação entre gênero e dança remete também a uma reflexão sobre o potencial da dança enquanto mediadora dos processos culturais e sociais que constituem os sujeitos de gênero. Em outras palavras, a dança é uma forma de pedagogia cultural, produzindo as diferenças de gênero e tornando-as parte dos corpos.

A literatura nacional e internacional tem registrado debates consistentes sobre gênero, dança, arte e educação (BOND, 1994; CLARK, 2004; DILS, 2004; STINSON, 1998, 2005; RISNER, 2007; QUINTANILHA, 2016; LESSA; TORTOLLA, 2015). Esses estudos têm apontado tanto para algumas possíveis situações de ensino-e-aprendizagem onde se perpetua a 
reprodução de valores culturais hierárquicos, sexistas, heteronormativos e cisnormativos, quanto estratégias para confrontá-los na educação em dança.

Conforme Sanderson (2001), Fisher (2007), Risner (2009) e Holdsworth (2013), muitas vezes, mesmo com a melhor das intenções, os esforços para fazerem meninos participarem de aulas de dança acabam por perpetuar códigos culturais sem questionamento. Estas tentativas, que Fischer (2007) chama de "estratégias machistas", centram-se em: a) tecer comparações entre esportes e dança, fazendo referências a dançarinos como atletas e esportistas (em vez de bailarinos), concentrando-se em movimentos de dança mais físicos e atléticos para os homens; b) minimizar o significante número de bailarinos que não são heterossexuais; c) comentar sobre bailarinos heterossexuais famosos, destacando as oportunidades para as "conquistas" heterossexuais para os dançarinos do sexo masculino.

Não problematizar como as normas de gênero constituíram historicamente mecanismos de reiteração por meio do treinamento do corpo na dança acaba muitas vezes contribuindo para a reprodução de representações hegemônicas. Professores e professoras que não refletem sobre questões de gênero em aulas de dança, reproduzem inconscientemente valores educacionais e políticos que "contribuem para manter não apenas o mundo da dança, mas o mundo mais amplo, tal como está" (STINSON, 1998, p.43), reforçando diferenças de oportunidades para meninos e meninas e educando para um processo de socialização hierarquizado. Assim, de uma forma muitas vezes não perceptível, formulações tradicionais e hierárquicas de um discurso dominante, que não necessariamente precisam ou queiram ser mantidos, são colocadas em operação e reforçados na dança (BERGHAUSER, 2013).

Algumas alternativas pedagógicas para a desconstrução dessas representações hegemônicas de gênero e de práticas sociais hierarquizadas, em aulas de dança, têm sido problematizadas. Por exemplo, Bond (1994), apontou um estudo em que meninas e meninos ao serem estimulados a criar movimentos livres em aulas de dança apresentavam inicialmente padrões sociais de movimentos corporais limitados às representações culturalmente atribuídas aos seus gêneros. E em um momento posterior, quando a professora trabalhou com o uso de máscaras de animais selvagens, isso pareceu afastar temporariamente as inibições ligadas ao gênero. Como resultado da utilização de um referencial simbólico não associado nem ao feminino nem ao masculino, a metodologia proposta fez com que as crianças diversificassem mais as suas movimentações, explorando novas possibilidades.

Feitoza (2011), Strack (2013), Quintanilha (2016), Ferreira e Samways (2018) e Nunes e Froehlich (2018) propõem mudanças nas danças a dois no Brasil, subvertendo a regra rígida das danças de salão onde somente os homens conduzem e somente as mulheres são 
conduzidas, ligada às noções de masculinidade ativa e feminilidade passiva. As/os autoras/es defendem a perspectiva da "escuta" do corpo do/a parceiro/a e da "co-condução", ressaltando a possibilidade da cooperação entre os condutores e conduzidos para trabalharem juntos, em uma relação de maior igualdade, independente das suas identidades de gênero.

Oliveira (2015) ressalta como em muitas construções artísticas contemporâneas, as performances em dança têm acompanhado as discussões de Butler (2017) e seguido a abordagem da paródia das normas de gênero, através da utilização dos signos de masculinidade e de feminilidade de forma caricaturada ou fora dos corpos que essas normas determinam. Tem acompanhado, em suma, aquilo que as performances dissidentes nãoheteronormativas e não-binárias tem instaurado, há muito tempo, nos contextos sociais LGBT+s, tais como as Drag Queens, Drag Kings e outros.

Nessa mesma linha, Lessa e Tortola (2015) descrevem uma proposta pedagógica de criação em dança onde as mulheres em cena vestem-se com trajes masculinos, usando os códigos culturalmente convencionados como "masculinos". As autoras investem, assim, na inversão da fórmula hegemônica onde certos símbolos culturais generificantes são associados à "masculinidade" e apenas ao corpo dos homens. Nesse sentido, elas defendem uma estratégia de subversão das normas para a produção de novos modelos de feminilidades.

Em geral, o impacto da reflexão pedagógica sobre o gênero no campo do ensino da dança tem gerado esses dois tipos de abordagens: a da desgenerificação e a da inversão simbólica. A abordagem da desgenerificação inclui metodologias onde os movimentos em dança são criados e estudados independentemente de como eles são significados na cultura hegemônica. Investem, assim, na possibilidade de que tanto meninos quanto meninas executem os mesmos movimentos, ampliando as suas possibilidades para além do que é permitido ou proibido ao homem ou à mulher. Já a abordagem da inversão simbólica tem apostado não na desgenerificação da dança, mas sim no uso dos códigos de feminilidade e de masculinidade fora do lugar. Ou seja, fora daqueles corpos que as normas hegemônicas determinam. Apostam, assim, na diversidade de performances de gênero possíveis.

\section{Conclusões}

A primeira coisa que se percebe, no que diz respeito à dança, é o fato de haver, no geral, um número maior de mulheres do que de homens. Essa ausência dos homens na dança é quase sempre justificada ou acompanhada por vozes que nos dizem que aos homens cabem as atividades mais "masculinas" e para as mulheres as mais "femininas". Essas são as vozes da 
cultura. Elas nos dizem que existem determinadas práticas sociais adequadas para cada sexo. E se, mesmo assim, os homens dançam, na maioria das vezes, entretanto, é apenas em alguns estilos e apenas de certos modos e maneiras de se expressar muito específicas.

Assim, a segunda coisa que salta aos olhos de qualquer pessoa que se aproxime do campo da dança é a pressuposição, bastante arraigada em nossa cultura, de existe um jeito "masculino" e um jeito "feminino" de dançar. E que o aprendizado das técnicas e dos gestos na dança, para homens e para mulheres, deve obedecer a esta oposição binária. Lógica paradoxal, porque, ao mesmo tempo em que afirma a existência do feminino e do masculino como energias "naturais" presentes nos corpos, isto é, como essências universais, investe ativamente na sua produção e até na sua regulação.

Problematizar as questões de gênero na dança vai muito além, no entanto, da preocupação em como motivar e atrair o interesse dos meninos para esta prática. Tal questão, da construção simbólica da noção de que a dança é um universo "feminino", articula-se de uma forma complexa a outras construções simbólicas. A dificuldade que muitos professores ou muitas professoras sentem em aproximar meninos da dança é apenas o elemento final de uma longa cadeia que começa com a construção de modelos identitários bastante limitados de "masculinidade" e de "feminilidade".

Embora possa parecer, ao leitor pouco habituado a tal temática, que a arte da dança esteja bem distante da reprodução de valores culturais sexistas, homofóbicos ou transfóbicos, pelo fato de ser uma área marcadamente inclusiva, cujos praticantes são muitas vezes pertencentes a minorias sociais (mulheres, gays, transgêneros, etc.), as reflexões apontadas aqui inserem-se dentro de uma perspectiva que compreende que todos nós, invariavelmente, podemos estar implicados em tudo isto.

A partir do entendimento que a construção do gênero ocorre a partir de certos investimentos da cultura sobre os corpos, compreende-se que a dança é uma dentre muitas práticas corporais implicadas na sua produção. Tal perspectiva nos leva, portanto, nos leva a refletir acerca de como a dança pode estar implicada na reprodução e repetição de normas de gênero ou em que medida se contrapõe a elas.

Duas dimensões, assim, da intersecção entre dança, corpo e gênero se revelam: como as danças chegam a existir, a partir das condições sociais e históricas; e como as danças, depois de terem sido produzidas, veiculam ou põem em circulação modelos simbólicos, representações e valores culturais que constituem o masculino e o feminino. A mútua influência entre a dança e o gênero demonstra ser, assim, um processo circular: concepções de gênero regulam as escolhas de vida dos sujeitos que dançam e produzem dança, e essa dança 
por eles assim produzida, fornece modelos que serem de referência simbólica para as escolhas de vida de outros indivíduos.

Qualquer perspectiva de ensino da dança que se proponha consciente e responsável deve levar em conta esse complexo processo da construção do gênero, a partir do qual a dança pode muitas vezes funcionar como um mecanismo de perpetuação de padrões culturais ligados à produção de hierarquias sociais. Atitudes aparentemente insignificantes, como ensinar para os alunos que existem movimentos de dança mais "masculinos" e mais "femininos", podem contribuir para perpetuar concepções bastante limitadas de gênero, ligadas a outras cadeias de representações.

Permitir que mulheres, através da dança, também explorem características e qualidades de movimento que culturalmente são tidas como "masculinas", tais como movimentos fortes, diretos ou explosivos, pode funcionar como uma forma de transformação das suas referências simbólicas. Da mesma forma, permitir aos meninos dançar das formas convencionadas como "femininas" pode tensionar os padrões de masculinidade dominantes. Por sua vez, utilizar noções de "masculino" e "feminino" de forma invertida, isto é, em corpos onde as normas dominantes não significam como "naturais", também pode auxiliar em processos educativos que estejam engajados na desnaturalização de certas formas de diferenciação que foram construídas social e historicamente.

Qualquer que seja a estratégia pedagógica, o que se revela central é o esforço para tornar o gênero uma variável consciente em todos os aspectos da educação pela dança. Sem essa reflexão consciente, o ensino da dança continuará a operar como um dispositivo que "fabrica" as masculinidades e as feminilidades a partir de normas culturais falocêntricas, heteronormativas e cisnormativas, reforçando lógicas sexistas, homofóbicas ou transfóbicas.

\section{Referências}

ANDREOLI, Giuliano Souza. Representações de masculinidade na dança contemporânea. Revista Movimento, Porto Alegre, v. 17, n. 01, p. 159-175, jan./mar. 2011.

BERGHAUSER, Tatiana Araújo. Problematizações sobre enfoques de gênero reducionistas ou distorcidos na Dança. 2013. Monografia (Especialização em Estudos Contemporâneos em Dança), Programa de Pós-graduação em Dança, Universidade Federal da Bahia, Salvador, 2013.

BOND, Karen Elizabeth. How "wild things" tamed gender distinctions. Journal of Physical Education, Recreation and Dance, v. 65, n. 2, p.28-33, 1994. 
BRITZMAN, Deborah. O que é esta coisa chamada amor? Identidade homossexual, educação e currículo. Revista Educação e Realidade, Porto Alegre, vol. 21, n.1, p. 7176, jan-jun, 1996.

BUTLER, Judith. Corpos que pesam: sobre os limites discursivos do "sexo". In: LOURO, Guacira Lopes (Org). O corpo educado: pedagogias da sexualidade.

Tradução de Tomaz Tadeu da Silva. Belo Horizonte: Autêntica, 2000. p. 110- 127.

Problemas de gênero: feminismo e subversão da identidade. Tradução de Renato Aguiar. Rio de Janeiro: Civilização Brasileira, 2017. 15² ed.

CANCLINI, Nestor Garcia. Diferentes, desiguais e desconectados. Rio de Janeiro: UFRJ, 2005.

CLARK, Dawn. Considering the issue of exploitation of young women in dance: K-12 perspectives, Journal of Dance Education, v. 4, n.1, p.17-22, 2004.

CLEGG, Helen; OWTON, Helen; ALLEN-COLLISON, Jacquelyn. The "cool stuff!: Gender, dance and masculinity. Psychology of Woman's Section Review, v.18, n.2, p. 06-16, 2016.

CONNEL, Robert William. Políticas de Masculinidade. Educação e Realidade, Porto Alegre, v.20, n.2, p.185-206, jul./dez. 1995.

COOK, Clive et al. 'What it takes': perceptions of mental toughness and its development in an English Premier League Soccer Academy. Qualitative Research in Sport, Exercise \& Health, v.6, n.3, p.329-347, 2014.

DAVIS, Angela. Mulheres, raça e classe. Tradução: Heici Regina Candiani. São Paulo: Boitempo, 2016.

DILS, Ann. Sexuality and sexual identity: critical possibilities for teaching dance appreciation and dance history. Journalof Dance Education, v. 4, n.1, p. 10-16, 2004.

FEITOZA, Jonas Karlos de Souza. Danças de Salão: os corpos iguais em seus propósitos e diferentes em suas experiências. 2011. 84p. Dissertação (Mestrado em Dança), Faculdade de Dança, Universidade Federal da Bahia, Salvador, 2011.

FERREIRA, Debora Pazetto; SAMWAYS, Samuel. Para além de damas e cavalheiros: uma abordagem Queer das normas de gênero na dança de salão. Educação, Artes \& Inclusão, Florianópolis, v.14, n.3, jul./set., p. 157-179, 2018.

FISHER, Jennifer. Make it maverick: rethinking the "make it macho" strategy for men in ballet. Dance Chronicle, v.30, p.45-66, 2007.

GARD, Michael. Dancing around the 'problem' of boys and dance. Discourse: Studies in the Cultural Politics of Education, v.22, n.2, p. 213-225, 2001.

HALL, Stuart. A centralidade da cultura: notas sobre as revoluções culturais do nosso tempo. Educação \& Realidade, Porto Alegre, v. 22, n.2, p. 15-46, jul./dez., 1997. 
HANNA. Judith Lynne. Dança, Sexo e Gênero: signos de identidade, dominação, desafio e desejo. Tradução: Mauro Gama. Rio de Janeiro: Rocco, 1999.

HASBROOK, Cynthia. Sociocultural aspects of physical activity. Research Quarterly for Exercise and Sport, v.64, n.1, p.106-115, 1993.

HOLDSWORTH, Nadine. 'Boys don't do dance, do they?', Research in Drama Education: The Journal of Applied Theatre and Performance, v.18, n.2, p.168-178, 2013.

KIMMEL, Michael Scott. A produção simultânea de masculinidades hegemônicas e subalternas. Horizontes Antropológicos, Porto Alegre, v.4, n.9, p.103-17, out. 1998.

LAQUEUR, Thomas Walter. Inventando o Sexo: corpo e gênero dos gregos a Freud. Tradução: Vera Whately. Rio de Janeiro: RelumeDumará, 2001.

LESSA, Patrícia. TORTOLA, Eliane. O corpo que dança e a construção da poética Drag King: um tango-ação, Revista Periódicus, v.1, n.4, p.76-90, 2015.

LOURO, Guacira Lopes. Gênero, Sexualidade e Educação:uma perspectiva pósestruturalista. Rio de Janeiro: Vozes, 2007.

LOURO, Guacira Lopes. (Org.).O corpo educado: pedagogias da sexualidade. Belo Horizonte: Autêntica, 2013a.

LOURO, Guacira Lopes. Um corpo estranho: ensaios sobre sexualidade e teoria queer. Belo Horizonte: Autêntica Editora, 2013b.

MEAD, Margareth. Sexo e Temperamento. São Paulo, Editora Perspectiva, 1988.

MEGLIN, Joellen. A.; BROOKS, Lynn Matluck. Where are all the women choreographers in ballet? Dance Chronicle, v. 35, n.1, p.1-7, 2012.

MEYER, Dagmar Estermann. Gênero, Sexualidade e Educação:Teoria e Política. In: LOURO, Guacira Lopes, FELIPE, Jane; GOELLNER, Silvana Vilodre. (Org.). Corpo, gênero e sexualidade: um debate contemporâneo em Educação. Petrópolis, RJ: Vozes, 2003.p.9-27.

MIGDALEK, Jack. The Embodied Performance of Gender.New York: Routledge, 2015.

MENEZES NETO, Hugo. "Damas e Cavalheiros": O estudo de caso das quadrilhas juninas de recife. In: SEMINÁRIO INTERNACIONAL FAZENDO GÊNERO: Corpo, violência e poder, 8, 2008, Florianópolis, Anais. Florianópolis, 2008.

NASCIMENTO, Diego Ebling. Macho, bailarino e homossexual: um olhar sobre as trajetórias de vida de professores dançantes. Dissertação (Mestrado), Universidade Federal de Pelotas, programa de pós-graduação em Educação Física, Pelotas, 2013. 
NICHOLSON, Linda. Interpretando o gênero. Revista Estudos Feministas. v.8 , n.2, 2000.

NUNES, Bruno Blois; FROEHLICH, Marcia. Um novo olhar sobre a condução na dança de salão: questões de gênero e relações de poder. Revista Educação, Artes \& Inclusão, Florianópolis, v.14, n.2, p. 91-116, abr./jun. 2018.

OLIVEIRA, João Manuel de. Tumultos de género: os efeitos de GenderTrouble em Portugal. Periódicus, v.1, n.3, p. 6-18, mai./out., 2015.

PASCOE, Cheri J. 'Dude, You're a Fag': adolescent masculinity and the fag discourse, Sexualities, v.8, n.3, p.329-346, 2005.

POLASEK, Katherine M.; ROPER, Emily A. Negotiating the gay male stereotype in ballet and modern dance. Research in Dance Education, v. 12, n.2, p.173-193, 2011.

PRECIADO, Beatriz. Manifesto Contrassexual: práticas subversivas de identidade sexual. São Paulo: n-1, 2014.

QUINTANILHA, Elisa de Brito. Parceria: Reflexões sobre damas e cavalheiros no contexto da dança de salão. Grau Zero. Revista de Crítica Cultural. V.4, n.2, 2016.

RISNER, Doug. Rehearsing masculinity: challenging the 'boy code' in dance education. Research in Dance Education. v.8, n.2, p. 139-153, 2007.

RISNER, Doug. Stigma and Perseverance in the Lives of Boys who Dance. Lampeter (WAL): Edwin Mellen, 2009.

RISNER, Doug. Bullying victimisation and social support of adolescent male dance students: an analysis of findings. Research in Dance Education, v.15, n.2, p.179-201, 2014.

SANDERSON, Patricia. Age and gender issues in adolescent attitudes to dance. European Physical Education Review, v.7, n.2, p. 117-136, 2001.

SANTOS, Éderson Costa. Um jeito masculino de dançar: pensando a produção das masculinidades de dançarinos de hip-hop. 2009. 124f. Dissertação (Mestrado em Educação), Faculdade de Educação, Universidade Federal do Rio Grande do Sul, Porto Alegre, 2009a.

SANTOS, Tatiana Mielczarski dos. Entre pedaços de algodão e bailarinas de porcelana: a performance artística do balé clássico como performance de gênero. 2009. 95f. Dissertação (Mestrado em Educação),Faculdade de Educação, Universidade Federal do Rio Grande do Sul, Porto Alegre, 2009b.

SARAIVA, Maria do Carmo; CAMARGO, Julieta Furtado. Dança do Ventre: ressignificações do feminino? In: SEMINÁRIO INTERNACIONAL FAZENDO GÊNERO: Corpo, violência e poder, 8, 2008, Florianópolis, Anais. Florianópolis, 2008. 
SILVA, Tomaz Tadeu da (Org.). Alienígenas na Sala de Aula: uma introdução aos estudos culturais em educação. Petrópolis: Vozes, 1999.

SCOTT, Joan. Gênero: Uma categoria útil de análise histórica. Educação eRealidade, Porto Alegre, v.20, n.2, p.71-79, jul./dez. 1995.

SOUZA, Andréa Bittencourt de. Cenas do masculino na dança: representações de gênero e sexualidade. Ensinando modos de ser bailarino. 2007. 151f. Dissertação (Mestrado em Educação), Faculdade de Educação, Universidade Luterana do Brasil, Canoas, 2007.

STINSON, Susan W. Seeking a feminist pedagogy for children's dance. In: SHAPIRO, Sherry B. Dance, power and difference: Critical and feminist perspectives on dance education. Champaign (USA): Human Kinetics, 1998. p. 23-47.

The hidden curriculum of gender in dance education. Journal of Dance Education,v.5 , n.2, p.51-57, 2005.

STRACK, Míriam Medeiros. Dama ativa e comunicação entre o casal na dança de salão: uma abordagem prática. 2013. 76p. Monografia (Especialização em Teoria e Movimento com Ênfase em Danças de Salão), Faculdade Metropolitana de Curitiba, São José dos Pinhais, 2013.

VAN DYKE, Jan. Gender and success in the American dance world. Women's Studies International Forum, v.19, n.5, p.535-543, 1996.

WELLER, Wivian. A presença feminina nas (sub)culturas juvenis: a arte de se tornar visível. Estudos Feministas, Florianópolis, v.13, n.1, p. 107-126, jan./abr. 2005.

WOODWARD, Kathryn. Identidade e diferença: uma introdução teórica e conceitual. In: SIVA, Tomaz Tadeu da; HALL, Stuart; WOODWARD, Kathryin. Identidade e diferença: a perspectiva dos Estudos Culturais. Petrópolis:Vozes, 2005. p. 07-72.

WRIGHT, Golden. Male dance educators in a female-dominated profession, Journal of Physical Education, Recreation \& Dance, v. 84, n.7, p.14-15, 2013. 